\title{
Tumor Results Link Group
}

National Cancer Institute

\section{Source}

National Cancer Institute. Tumor Results Link Group. NCI Thesaurus. Code C117412.

A sequence of characters used to link multiple tumor results records to a single finding. 